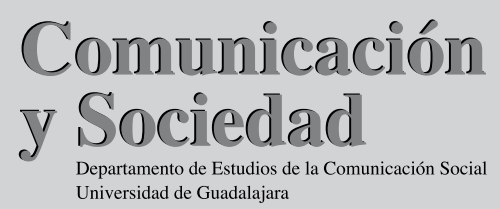

\title{
Flou: invención y ordinario del periodismo*
}

\author{
DENIS RUELLAN 1
}

En este artículo se analiza y contextualiza el modelo de formación identitaria del periodismo en Francia, al que el autor denomina el professionnalisme $d u$ flou, un modelo cuya gestión del espacio y de las relaciones profesionales ha sido fluida y profundamente pragmática. El trabajo da cuenta, también, de la pluralidad de discursos en torno al proceso continuo de construcción y de transformación de la identidad del grupo profesional de los periodistas, y confronta la mirada unívoca y esencialista del periodismo defendida por este grupo, con una perspectiva que considera al periodismo como "práctica social" co-construida por actores interconectados en el corazón de un espacio público ampliado.

PALABRAS CLAVE: identidad profesional, estudios sobre periodismo.
This article contextualize and analyze the model of construction of journalistic identity in France, a model whose management of the space and the professional relations has been fluid and deeply pragmatic and to which the author denominates professionalisme $\mathrm{du}$ flou. The work also gives account of the plurality of speeches around the continuous process of construction and transformation of the identity of the professional group of journalists, and confronts the univocal and essentialist glance of journalism defended by the group, with a perspective that considers journalism as a "social practice", one that is co-constructed by actors interconnected in the heart of an extended public space.

KEY WORDS: Professional identity, journalism studies.

* Traducción del francés al español por Christine Pignard.

1 Centre de Recherches sur l'Action Politique en Europe, UMR CNRS, Université de Rennes 1, Institut d'Études Politiques de Rennes. Observatoire des NTIC et des Métiers, Lannion.

Correo electrónico: denis.ruellan@univ-rennes1.fr 
Dentro de la perspectiva interaccionista de la sociología de las profesiones hemos desarrollado la tesis de que el periodismo está hecho

de amalgamas flexibles de segmentos que persiguen objetivos diferentes de diversas maneras, y que permanecen más o menos frágilmente bajo una común denominación en un periodo específico de la historia" (Bucher, 1961).

Señalamos que si la imprecisión de las fronteras, de los perfiles profesionales y de las prácticas era una necesidad vital, el rigor sólo engendraría conflictos y dificultades. Al expresar la capacidad plástica del grupo a adaptarse a las transformaciones, el modelo del professionnalisme du flou (Ruellan, 1993) explicaba la formación identitaria del periodismo en Francia y permitió comprender el modo de gestión de sus estructuras y límites para el grupo actual, formulando la tesis de que esta administración fluida de las fronteras era el resultado de un dispositivo eficientemente ajustado para enfrentar las fluctuaciones, debidas principalmente a las presiones ejercidas en los perímetros del mercado de trabajo. En trabajos complementarios (Ruellan, 1997) hemos continuado con la tarea de mostrar cómo la profesión de periodista se había asentado

alrededor de un eje central: la monopolización de un segmento del mercado de trabajo concentrado en controlar la incertidumbre de la relación salarial o mercantil (Paradeise, 1988).

en defenderse de las competencias en el mercado del empleo y controlar sus desarrollos al apropiarse de una posición simbólica capital, perfectamente representada por la carte de presse.

En efecto, a lo largo del proceso que les permitió a los periodistas franceses pasar de un estado social mal definido a un reglamento profesional (el que se adquirió por la Ley de 1935), ellos han endurecido progresivamente el discurso sobre la profesión, el profesionalismo y la profesionalización. Este discurso revela una estrategia esencialista dirigida a establecer al periodismo como componente intangible e indiscutible de las sociedades democráticas; el mismo que pretendería 
que sólo los profesionales seleccionados, en las competencias verificadas, organizados dentro de un grupo, tuvieran el derecho a la identidad y a la práctica periodísticas; evocando de inmediato la idea de "orden profesional" para dar estructura al grupo y limitar el acceso al mismo. Apoyados en organizaciones hermanas en Occidente (los primeros congresos internacionales de periodistas han tenido lugar desde finales del siglo XIX), y con el convencimiento de los partidos republicanos que concebían un vínculo consustancial entre información y democracia, los periodistas se organizaron en un sindicato poderoso. También movilizaron a la universidad para dotar de cientificidad a un discurso casi sectario. Este discurso profesionalista era un arma de combate territorial e identitario, y cuando triunfó probó que el objetivo era el acceso de los periodistas al reconocimiento social, al respeto individual y colectivo. Sin embargo, en el fondo, nada cambió dentro de la formación profesional del grupo, todo permanecía como los periodistas desearon que permaneciera: en el flou, lo que prueba perfectamente la gestión del territorio por la carte de presse.

Así, los periodistas franceses obtuvieron que su documento de identidad profesional fuera expedido por una autoridad paritaria bajo control del Estado; pero rechazaron que el procedimiento fuera de carácter obligatorio, de tal suerte que desde que se votó la ley y se aplicó en 1937, los periodistas ejercieron su oficio sin necesidad del mismo. Su concesión no tenía por condición la posesión de un título, y esto hizo que menos de $20 \%$ de los periodistas (titulares del documento) tuvieran una formación profesional; los errores deontológicos no pueden ser invocados para refutar su asignación o su renovación anual. Y es que no es su posesión la que otorga el derecho a la más importante disposición de la ley, sino la cláusula de conciencia; en efecto varias jurisprudencias recordaban que tal documento no es más que un indicador de identidad profesional;2 esto puede probarse bien por otros medios, por ejemplo un contrato de trabajo.

A pesar de su pésima eficacia material, este documento es expedido desde hace setenta años; es muy solicitado y, a su vez, envidiado, y se

2 Nota del traductor: en algunos países de América Latina, como México, la identidad profesional se conoce como cédula profesional. 
puede observar que adquirió un poder simbólico considerable al permitir al grupo profesional controlar las transformaciones del mercado de trabajo de su profesión. En efecto, es de carácter atributivo, según las reglas definidas por la ley, por la comisión compuesta de representantes de los sindicatos de asalariados y de las organizaciones profesionales; y muy a pesar de la cantidad de trabajo anual (actualmente los periodistas son más de 37 000, y normalmente se necesitan renovación de cartas y revisión de más de tres mil nuevas solicitudes), dos miembros dan una opinión sobre cada expediente y los "casos difíciles" son objeto de largas discusiones en sesiones plenarias. Ya cuando se adoptó la ley, no había podido reservarse la concesión del documento de identidad a redactores de artículos de prensa escrita solamente; fue preciso "asimilar" perfiles particulares como los de los traductores, los revisores, los estenógrafos, los secretarios de redacción, los fotorreporteros y, años más tarde, los de los reporteros de la radio y la televisión. Adicionalmente, y de modo creciente en los últimos veinte años, no dejaron de presentarse nuevos perfiles ante la comisión de revisión y expedición. Esta presión hizo volar en fragmentos muchos principios del perfil típico-ideal del periodista, diseñado por los sindicalistas del periodo situado entre las dos guerras mundiales.

En efecto, la ley de 1935 clasifica al periodista profesional francés dentro de cuadros jurídicos y organizacionales: en la empresa mediática, en una relación subordinada, en un continuum de fabricación. Este encuadramiento se ha desplazado: por una parte la diversidad de los tipos de organización, por otra la mutación de funciones profesionales y, por último, la desregulación de la relación de empleo, llevando al grupo hacia nuevos referentes. Para ser periodista ya no es necesario estar empleado en una empresa periodística; la noción de publicación es muy amplia; el ingreso puede ser bajo y complementado con algún otro (inclusive en la comunicación publicitaria); el vínculo con la administración no es ya una prohibición; las funciones técnicas adicionales son aceptadas; el trabajo intelectual ya no trata forzosamente de actualidad, la externalización del trabajo de la empresa es una realidad que se toma en cuenta. Estas evoluciones en los dispositivos técnicos, organizacionales y también conceptuales son probablemente parte de la explicación del consi- 
derable crecimiento del número de periodistas después de medio siglo: de 36500 en 2005, pasó a 32000 en 2000, 26000 en 1990, 16000 en 1980, 13000 en 1973, 10000 en 1965, y 6600 en 1953. Casi seis veces más numerosos, los periodistas de hoy son los mismos de ayer pero muy diferentes a la vez (Ruellan, 2005).

Esta apertura de los perfiles se explica de muchas maneras. El empleo es en Francia, como en cualquier otra parte, cada vez más desregulado, y esta condición afecta también a las profesiones muy definidas, como es el caso del periodismo. Otra razón se debe a la extraordinaria transformación del panorama de la comunicación y de la información. Hasta la Segunda Guerra Mundial, los periodistas y los publicistas se dividían el mercado de trabajo, el cual era reducido. Después llegaron las funciones de relaciones públicas, las de productores de radio y de televisión, y desde hace poco la de los redactores de los sitios de internet. Sobre todo los medios se multiplicaron masivamente, en el habitual espacio de las mercancías, pero también al vincularse con organizaciones (las administraciones públicas, las asociaciones, los sindicatos, las empresas) que a la vez son fuentes y productoras de medios. Ahora bien, esta proliferación ha sido un choque para los periodistas. Ellos han debido inventar estrategias de respuesta a estos movimientos. La primera la anatema, el discurso de la pureza periodística resistente a la violación de la información de parte de la comunicación; este discurso parecía cada vez menos pertinente a medida que se afirmaba un "periodismo de fuente" (Sant'Anna, 2005) de calidad que servía de referencia a los periodistas "tradicionales". La segunda, la estrategia de la amalgama: la formidable evolución del mercado de la información no se desarrolló en los medios mercantiles tanto como en las organizaciones; salvo al permitir a otro grupo que se abriera su propia opción, los periodistas se veían obligados a incorporar a esos individuos que iban inventando un nuevo territorio profesional.

Es esa gestión fluida del espacio y de las relaciones profesionales, generada por un profundo pragmatismo, que hemos querido entender en la expresión professionnalisme du flou. Esta fórmula traduce también la pluralidad de los discursos operando en el proceso continuo de construcción y de transformación de la identidad, perspectiva heurística compartida por varios investigadores de quienes evocaremos sus trabajos en la primera parte de este artículo. A la univocidad 
de los argumentos esencialistas defendidos por el grupo profesional, parece también necesario oponer la diversidad de actores, múltiples e interconectados, que contribuyen ayer como hoy, a construir el periodismo como práctica no solamente profesional, sino social, compartida, co-construida en el corazón de un espacio público ampliado. Esta perspectiva ha sido sostenida por un grupo científico internacional, al que nos referiremos en una segunda parte, antes de proponer en la última sección de este artículo una nueva mirada de investigación, más abierta todavía, cuya ambición final es sugerir una renovación profunda de las problemáticas de los estudios sobre el periodismo.

\section{INTER-DISCURSOS Y DISPERSIÓN}

En su trabajo de tesis (2006), María Elena Hernández Ramírez ha estudiado el proceso de renovación de la profesión del periodismo en México, la que debía traducirse en reforzamientos de las estructuras grupales, de los cursos y medios de formación, en mantener distancia entre el Estado y los periodistas, en una evolución hacia una mayor ética profesional. Hernández Ramírez demostró que este cambio inició no por un movimiento autónomo del grupo de periodistas, sino gracias al gobierno de Carlos Salinas de Gortari que, en 1988, con un discurso "modernizador", propició una intensa reflexión y las reformas de los usos relacionales entre la prensa y las autoridades. ¿Acabó acaso con esta dependencia de la prensa para con el gobierno? Hernández Ramírez adelanta que esta tutela es en lo sucesivo llevada a cabo por la vía económica, porque el Estado permanece como un anunciador esencial y porque la oligarquía reproduce su autoridad en la posesión de los medios dentro del espacio comercial. La tesis subraya, también, los motivos de esta repentina "modernización" apoyada por el poder: al mismo tiempo que México acordaba su inserción en el mercado liberal norteamericano, trataba también de mostrar su liberalismo, de extender esta nueva convicción ideológica hacia los medios, de hacer valer la libertad de prensa. Hernández Ramírez concluye:

sostenemos la hipótesis según la cual las exigencias internacionales reque- 
ridas por la firma del Tratado de Libre Comercio para América Norte (TLCAN) constituyeron aquello que condujo a la presidencia de la República a tratar de "sanear" aquel modo de relación que había proporcionado al sistema tantas lealtades y complicidades, debido a que México debía particularmente probar a la comunidad internacional que la libertad de expresión existía sobre su territorio, que se podían encontrar medios independientes y plurales y que se caminaba hacia la democracia. (...) Al inicio de los 90, las discusiones se volcaron en torno de la "profesionalización" del periodismo mexicano, estas fueron alimentadas por un discurso político pero igualmente por una tentativa corporativista de ganar terreno sobre el escenario de los derechos laborales (...). No obstante, es cierto que si este "impulso corporativista" pudo manifestarse, fue gracias al régimen autoritario que abrió espacios permitiendo con ello escuchar las viejas demandas de cierto sector de periodistas. Esta apertura ciertamente pudo ser vista como el resultado de la estrategia de proyección internacional del gobierno salinista pero igualmente como un beneficio para la institución de la prensa, originada por la visión del periodismo que defendían los asesores de Salinas en materia de comunicación (periodistas y universitarios con trayectoria brillante la mayoría) entre los cuales había total interés para algunos en que tales relaciones se "depuraran".

La autora muestra, de esta manera, que la profesionalización de un grupo de periodistas es un proceso contingente de discursos políticos externos; asimismo, de trayectorias sociales que no le conciernen más que parcialmente, de mutaciones económicas globales de las cuales no es o no será más que uno de los actores indirectos. Su propósito está en consonancia con la historia francesa. Los gobiernos republicanos fueron esenciales para apoyar el surgimiento de un tejido profesional, en el esquema asociativo, antes de la Primera Guerra Mundial, y para el sindicalismo, luego, en el periodo de entreguerras. Convencidos de la consustancialidad entre la prensa y la democracia, entre la libertad de la primera y la transparencia de la segunda, los republicanos jugaron a los periodistas contra el oscurantismo: el practicado por los políticos conservadores, y luego por los dueños de la prensa. Rehusando el otorgamiento de un estatus profesional para los periodistas, los patrones pretendían conservar, sin reparto, su poder en el seno de las empresas y 
extenderlo a todo el espacio público a través de la potencia de sus tirajes y de la ampliación de sus relaciones a veces ilegales (cfr. los escándalos financieros repetidos en los años 20 y 30). Las leyes sociales de 1936 y la obligación de negociación de 1937 acabarían con esas pretensiones; y la ley de 1935 sobre el estatuto de los peridodistas permitió, al aumentar la autonomía hacia los patrones, limitar ciertas influencias políticas nefastas de los mismos.

Esta perspectiva pone también en consideración una idea normalmente compartida por numerosos investigadores, según la cual la construcción de un grupo es un proceso continuo de agregación de agentes, que conducirá ineluctablemente a la formación de una identidad. Por lo contrario, Sandrine Lévêque (1996) ha defendido que

Lejos de ser continua, la profesionalización es un proceso caótico. De este modo hemos puesto en evidencia los intereses divergentes, $\mathrm{y}$ a veces incluso antagónicos, que cruzan al grupo profesional. El análisis de una especialidad, como la del periodista social, muestra la heterogeneidad de agentes comprometidos a lo largo de todo el siglo 20 en la lucha para lograr el reconocimiento de la profesión periodística, y su contribución a mantener la existencia del grupo reinvindicando, desde su especificidad, su pertenencia a dicho grupo. En este sentido, la unidad de la profesión lleva también a la diversidad de aquellos que intentan imponer una definición.

Y dentro de esta lucha, los periodistas están especialmente ocupados con los dueños de los medios, que se esfuerzan en hacer valer una concepción de periodismo conforme a sus intereses de empresarios. En los Estados Unidos, Dan Schiller demostró cómo los conceptos de objetividad y profesionalismo que acompañaban a la introducción de normas técnicas dentro de las prácticas periodísticas, sirvieron para legitimar a la prensa comercial en el papel de protectora del interés público (public good), desde 1840 más o menos:

Codificación explícita de las técnicas periodísticas que son objetivamente seguidas, como el periódico que buscó por un lado mantener su aparente independencia del comercio, y por el otro, de las interpretaciones autointeresa- 
das venidas desde sus fuentes informativas. La ecuación de profesionalismo con la práctica del reporte objetivo de noticias fortaleció al periodismo y al mismo tiempo sirvió para responder a sus necesidades comerciales, las que legitimarían la importancia de su papel institucional como el autoanunciado defensor del bien público33 (Schiller, 1979)

Esos autores sugieren que el discurso sobre la profesión no debería ser comprendido como unívoco; el mismo es el producto de una pluralidad dircusiva; su base son los inter-discursos, perspectiva conceptualizada por Roselyne Ringoot (2005). Inspirada en Michel Foucault, la autora concibe al periodismo como una "formación discursiva" cuya construcción es la puesta en orden del desorden de discursos dispersos, en el sentido de que son producidos por autores de todo tipo. De la misma forma que Foucault sostuvo que la locura es eso que dicen, por las palabras, por los actos y los dispositivos, no únicamente los médicos, sino también los pacientes, los administradores, la iglesia, las tecnologías, las prácticas, las investigaciones, la gestión, las políticas públicas, Ringoot adelanta que el periodismo es eso que los actores de la época dicen y hacen, y hay que considerar como actores no solamente a los que el proceso histórico hizo designar como profesionales, sino también a todos los que por su discurso y sus prácticas llegan a transformar las percepciones: la variedad creciente de los periodistas, los editores, los poderes públicos, las escuelas, los públicos..., y finalmente todos aquellos que se apropian del periodismo, al entenderlo como dispositivo (los medios) y práctica (la información y su enunciación). Por lo tanto el trabajo del investigador es el de describir precisamente este desorden con el fin de resaltar las fuerzas de orden, por ejemplo, a través de los

3 Explicit codification of the techniques of journalistic objectivity followed, as the newspaper sought to maintain its apparent independence from commerce on one side and, on the other, from the selfinterested interpretations of events proferred by its sources. The equation of professionalism in journalism with the practice of objective news, reporting thus gratified the occupation while simultaneously serving the encompassing need of commercial journalism, to legitimate its major institutional role as the selfannounced protector of the public good. 
procesos de fabricación de la información, las modalidades de enunciación, las estrategias de los actores. Esta noción de dispersión facilita pensar la heteronomía del periodismo como algo constitutivo e intrínseco. Permanece, así, un concepto embrionario libremente adaptado de la proposición inicial de Foucault. Pero si hay dispersión, no es aleatoria ni indefinida. Dispersión, dentro del esquema de la formación discursiva, no significa esparcimiento: esta siempre está circunscrita dentro de un juego de relaciones. La tensión entre orden y dispersión del discurso aparece entonces en el anclaje de las lógicas de actores diversificados. Si se reconoce un orden del discurso periodístico, se reconoce también una dispersión extradiscursiva. Dentro de esta apropiación conceptual, se trata de considerar cómo un discurso identificado e identificable es constituido bajo la acción de factores y actores heterogéneos.

\section{INVENCIÓN PERMANENTE}

Roselyne Ringoot desarrolló su proposición en relación con Jean-Michel Utard, en el marco de la Red de Estudios sobre el Periodismo. ${ }^{4}$ Después de interesarse en la irrupción del internet dentro del espacio informativo local (Damian et al., 2002), tal red analizó la hibridación de los géneros mediáticos, expresión que acordaba problematizar los fenómenos de porosidad, de transferencia y mutación de las identidades (discursos y prácticas) en las actividades de información y de comunicación. Esta perspectiva colectiva continuaba con nuestra manera de enfocar las relaciones del periodismo con las artes gráficas, la literatura, la ciencia, la publicidad o la comunicación (Ruellan, 1994), las mutaciones organizacionales unidas a la tecnologización de las salas de redacción y sus implicaciones identitarias (Ruellan, 1998), los procesos de ingreso a la profesión (Marchetti, 2001) y las transformaciones en el mercado de trabajo. Continuidad, pero sobre

4 Formada por veinticinco investigadores de Brasil (Brasilia), Francia (Aixen-Provence, Grenoble, Lannion, Lyon, Nice, Paris, Saint-Denis de la Réunion, Strasbourg, Verdun), de México (Guadalajara) y de Canadá (Québec), esta red, trabajando de manera cooperativa y descentralizada, estudia las transformaciones del periodismo. 


\section{todo densificación:}

- conceptual con el aporte de Foucault que, con la dispersión y la formación discursiva, procura un esquema teórico más riguroso que el del flou (en el que tenemos que reconocer cierta imprecisión interna...) e igual de heurístico;

- problemática porque los trabajos de la Red... harán estallar radicalmente las últimas transformaciones esencialistas, para colocar el estudio del periodismo en una perspectiva epistémica radical, la de la invención permanente del periodismo:

La noción de dispersión en la formación discursiva periodística trata de rendir cuentas de las transformaciones, e incluso las mutaciones que se observan en los medios sin asimilarlas con los movimientos de extensión o al contrario de sumersión del modelo profesional de la práctica periodística. Lo que esta noción afirma es que las nuevas prácticas surgen de manera dispersa, es decir, sin que puedan ser relacionadas a un origen único. Y por tanto, lo que esta noción cuestiona, es la posibilidad de identificarlas como periodísticas, independientemente de las normas históricamente construidas. No es que no tengan sus razones sociales, ni que la institucionalización del periodismo, tal como se hizo, no fuera una dimensión necesaria de la lógica democrática. Pero el periodismo por si no puede pretender ocupar un espacio que desborda un territorio o una función para extenderse a otras prácticas de producción de información y de saberes sobre el mundo, o incluso de visiones del mundo. Es así como se debe entender la idea de invención permanente del periodismo. La alusión explícita al título de la obra de Thomas Ferenczi (1993) retiene la idea que la práctica periodística se construye por diferenciación, o incluso por la ruptura con otras prácticas, y constituye por tanto un campo identificable. Pero la contradicción que plantea la ruptura como un acto continuo quiere decir la imposibilidad de identificarla exclusivamente con una esencia que posibilitara su encarnación en una profesión.

Así, la Red... observó la invención en sus formas diversas: la prensa consumista, los diarios gratuitos, las palabras cotidianas, los dispositivos de autopublicación; 5 otros trabajos trataron las políticas públicas de

5 Trabajos publicados en la obra de Ringoot (2005). 
incitación a la publicación en la Bretaña, las relaciones del periodismo y de la comunicación en Quebec, la multiplicación de los discursos institucionales en Brasil, la convergencia y las sinergias productivas de la prensa en México, la creación de un espacio público en una sociedad de interconocimiento cultural en la Reunión. ${ }^{6}$

Esta nueva proposición incita a disociar definitivamente la categoría profesional de la actividad periodística, al periodista del periodismo. Este es una práctica social irreductible a un espacio único; desde siempre, el periodismo, entendido como acto de información que da un individuo a las masas a través de medios de comunicación, ha sido practicado, independientemente de los esquemas socioprofesionales y organizacionales. El periodista como trabajador es una invención de fin del siglo XIX, de la industrialización de la prensa: si bien ya existían algunas centenas de empleados antes de 1860, el fenómeno sale de la marginalidad con el éxito popular del periódico a muy bajo precio. El periodista, como grupo, es una creación de la época de entreguerras cuando, del movimiento asociativo que no había llegado a reunir los intereses de individuos perdidos en una "gran familia" demasiado grande, surgió el sindicalismo reivindicativo en oposición a los dueños de los medios. El trabajador y el grupo establecieron una representación del periodismo reducida a ellos mismos, lo que está en el orden de las reglas del juego social: erigieron su práctica en un saber específico a través de los manuales y de las escuelas (desde los fines del siglo XIX); intentaron establecer una "ciencia de la prensa" con la creación de lugares de investigación para fines de los años 30;7 algunas veces pretendieron la dirección de los medios al considerarse como la esencia de estos (cfr. el movimiento de las sociedades de redactores en los años 60); sobre todo obtuvieron una ley que

6 Trabajos por publicarse bajo la dirección de F. Demers y D. Augey (2007).

7 En 1937 fue creado, en el seno de la Universidad de París, el Instituto de Ciencia de la Prensa, el cual era codirigido por universitarios y dirigentes sindicales del periodismo, y dio lugar a la primera revista de estudios, $\mathrm{Ca}$ hiers de la presse (Cuadernos de la prensa). En los años 90, el proyecto de una investigación iniciada por los círculos profesionales fue relanzado por dos de las principales escuelas: la Escuela Superior de Lille y el Centro de Formación de Periodistas. 
tendía a otorgar legitimidad solamente al profesional en el ejercicio del periodismo: al definir al periodista profesional, la ley de 1935 permitió al grupo enviar a la ilegitimidad a aquellas prácticas no profesionales y así arrogarse el periodismo. Sin embargo, este continuó existiendo fuera del grupo, poniéndose en práctica entre otros actores que estuvieran al margen del grupo o que se distinguieran netamente de él.

Gracias a las capacidades de amalgamar conferidas por el flou, el grupo integra gradualmente tales márgenes. Como lo señalamos líneas arriba, desde la redacción de la ley, se había previsto tal proceso de amalgamiento al señalar que los perfiles particulares de los traductores, correctores, estenografistas, secretarias de redacción, fotorreporteros debían ser "asimilados". Y llegaron los reporteros de la radio y de la televisión algunos años después, luego los técnicos de la edición de la página y de la captación de las imágenes de video, los asalariados de las organizaciones no mediáticas, $\mathrm{y}$, recientemente, los periodistas en línea. Recién llegados a los espacios del periodismo, los constructores de los blogs, de los que una fracción (ultraminoritaria, pero lo importante no es el número sino el sentido del acta) empieza a tocar a la puerta del grupo para que se les reconozca esa actividad, que siguen presentando todavía (fines de 2006) a través de un discurso de doble pretensión con respecto a la profesionalización y a la autonomía, dialéctica característica de los laureados.

Este proceso agregativo resalta el vigor del periodismo fuera de las fronteras del grupo. Si este amalgama constantemente nuevos perfiles por deseo de controlar el desarrollo y no dejarse desbordar por la irrupción de un grupo concurrente, es la clara prueba de que el periodismo existe y que se inventa más allá de los límites categorizables, así es cómo se reinventa de manera permanente.

\section{EL PÚBLICO PERIODISTA}

O LO ORDINARIO DEL PERIODISMO

Si logra explicar la dinámica de transformación, el modelo agregativo mantiene la mirada focalizada sobre el propio grupo periodístico y reenvía a la sombra a otras dimensiones de la práctica del periodismo. En este modelo, el periodismo no se distinguiría de las otras actividades que, finalmente, se logran transformar debido a la incorporación de prácticas 
innovadoras, que en parte nacen fuera de los límites de la legitimidad. Ahora bien, nos parece que la nueva frontera de los estudios sobre el periodismo debería cuestionar la dimensión ordinaria, no profesionalizada y sin pretensión de serlo un día, poseedora de una lógica propia e independiente (que no significa sin vínculo) de prácticas instituidas. Desde siempre, individuos solos o mayoritariamente organizados se han apoderado del periodismo para dirigirse a una comunidad, pretendiendo la voz en un espacio público ampliado, liberándose de las voces autorizadas. Los canards del antiguo régimen, los periódicos políticos de la Revolución, los boletines asociativos, las radios comunitarias, los webzines (autopublicación colectiva), y recientemente la explosión de los blogs, no son sino estas expresiones unipersonales orientadas hacia el universo y, con todo, atadas a espacios sociales precisos.

No es sino un ordinario del periodismo, según los términos con que Michel de Certeau y Luce Giard (1983) definían a la cultura ordinaria opuesta a la cultura de masas:

la primera nos remite a una producción masiva que simplifica los modelos propuestos para ampliar su difusión. La segunda concierne a una "consumición" que trata el léxico de los productos en función de códigos particulares (a menudo el trabajo de los practicantes) y en vista de servir a intereses propios. Una tiende hacia a la homogeneización (...) aunque esconda esta inclinación fundamental bajo variaciones superficiales destinadas a fortalecer la ficción del "nuevo producto", del "acontecimiento esencial", etc. La otra esconde una diversidad fundamental de las situaciones, los intereses, los contextos de cultura o de psicología, bajo la repetición aparente de los objetos de los cuales se sirve. A la uniformidad que es la regla ineluctable de la producción en masa, responde la pluralidad de los reempleos y de las costumbres sociales. La pluralización nace del uso ordinario, de esa reserva inmensa no sólo de número (la masa) de gentes, sino de lo múltiple (las diferencias de los individuos y de los grupos).

De Certeau y Giard se pronuncian por un análisis del

hacer con, aqui y ahora, es decir un acto singular ligado a la situación y a las circunstancias, a la presencia de actores particulares. En este sentido, la 
cultura ordinaria es en primer lugar una ciencia práctica del singular.

La investigación sobre el periodismo debe en adelante hacer rumbo hacia este hecho primordial, novedoso por la importancia que cobra al aprovecharse de las disponibilidades tecnológicas: la irrupción del público periodista, esta singularización del acto de producir y difundir información de la cual se apoderan los individuos en prácticas variadas; las que pueden ser incorporadas por los medios masivos de comunicación, utilizados para alimentar los contenidos y satisfacer las supuestas esperas de los lectores; ellas también son a menudo liberadas de los espacios tradicionales, libradas de la tutela tecnológica y financiera que mantiene la autoridad del grupo profesional y de los editores. Este estudio del receptor designado que se hace emisor, debe comenzar porque esta singularización del acto y del ser periodístico es capaz de trastornar la identidad del grupo profesional: si los públicos (y las fuentes, las cuales se han profesionalizado para imponer su voz en la agenda como lo mostró Schlesinger [1992]) empiezan a ocupar tanto el espacio del reportaje (la recolección de los hechos) que construyó la identidad del periodismo moderno de fines del siglo XIX, ¿cuál será el territorio de los periodistas profesionales? Ya que la información se está convirtiendo en un valor banal y gratuitamente difuso (los radios y televisiones en continuo, los diarios, los celulares, los flujos RSS), ¿qué aportarán los periodistas que los públicos no sepan ya? Valor agregado, análisis, puesta en perspectiva, reflexión, capacidad de comunicar, dicen algunos. Competencia de agregación, de regulación, de certificación, dicen otros. Las dos predicciones no son contradictorias, hasta parecen combinarse. Podrían significar dos desplazamientos, que también son retornos: de un lado, los periodistas reajustarían su legitimidad profesional en el centro del continuum de producción, en las funciones de mediación y de regulación de los contenidos venidos de voces externas, expresiones que ellos tendrían la misión de dirigir hacia otros; por otra parte, la figura del autor, este trabajador dotado de autonomía que desapareció bajo la imagen del asalariado que la profesionalización y la industrialización impusieron, podría recobrar un lustro perdido en el periodismo desde hace tiempo. El mercado del trabajo del periodismo podría así ser segmentado en dos conjuntos: en el interior de las empresas, asalariados, reguladores de contenidos de información, en el cual la producción sería principalmente externalizada, 
comprada a los autores, parcialmente profesionalizados y sometidos a una concurrencia generalizada de fuentes y de públicos. Dentro de esta hipótesis, el periodismo operaría en un eterno retorno hacia sí mismo, hacia las condiciones de su nacimiento en el siglo XVII, cuando Théophraste Renaudot, editor de la Gazette ${ }^{8}$, rodeado de algunos secretarios de redacción, encontraba sus noticias en la ciudad entre informadores que no dejaban de ser sus lectores.

\section{Bibliografía}

BUCHER R. \& Strauss A. (1961) "Profession in process", American journal of sociology, vol. 66.

CERTEAU de M. \& Giard L. (1983) L'ordinaire de la communication, rapport au Ministère de la Culture, Dalloz.

DAMIAN D., Ringoot R., Ruellan D., Thierry D. (dir.) (2002)Inform@, tion.local Le paysage médiatique régional à l'ère électronique, L'Harmattan.

HERNÁNDEZ-RAMÍREZ M.E. (2006) La “professionnalisation” $d u$ journalisme au Mexique : le discours "modernisateur" de Carlos Salinas de Gortari sur les relations presse-gouvernement, tesis de doctorado de la Universidad de París 8.

LÉVÊQUE S. (1996) "La construction journalistique d'une catégorie du débat public. Spécialisation journalistique et mise en forme du social", tesis de doctorado de la Universidad de París 1.

MARChETTI D., Ruellan D. (2001) Devenir journalistes. Sociologie de l'entrée sur le marché du travail, La documentation française.

PARADEISE C. (1988) "Les professions comme marchés de travail fermés”, Sociologie et sociétés, vol. XX, núm. 2, octubre.

RINGOOT R., UTARD J.M., (2005) "Genres journalistiques et "dispersion” du journalisme", en Ringoot R., Utard J.M. (dir.), Le journalisme en invention, nouvelles pratiques, nouveaux acteurs, Presses Universitaires de Rennes.

RUELLAN D. (1993) Le professionnalisme du flou, identité et savoirfaire des journalistes français, PUR.

— (1994) "Les frontières d'une vocation", en Lacan J-F., M. Palmer,

8 La primera publicación regular en Francia (1631). 
Ruellan D., Les journalistes - stars, scribes et scribouillards, Syros.

- (1997) Les “pros” du journalisme. De l'état au statut, la construction d'un espace professionnel, PUR.

— \& Thierry D. (1998) Journal local et réseaux informatiques. Travail coopératif, décentralisation, identité des journalistes, L'Harmattan.

- (2005) "Expansion ou dilution du journalisme ?", Les enjeux de l'information et de la communication, http://www.u-grenoble3.fr/ les_enjeux/pageshtml/art2005.php, junio.

SANT'ANNA F. (2005) Midia das fontes: o difusor do jornalismo corporativo, Brasilia: Casa das Musas.

SCHILLER D. (1979) "An historical approach to objectivity and professionalism in America news reporting", Journal of Communication, Autumn.

SCHLESINGER P. (1992) "Repenser la sociologie du journalisme. Les stratégies de la source d'information et les limites du média-centrisme", Réseaux, núm. 51, CNET. 
